\title{
From Deed to Word: gapless and kink-free Enactivism
}

\author{
In memoriam John V. Canfield (1934-2017) ${ }^{1}$
}

\begin{abstract}
In their most recent book, Evolving Enactivism: Basic Minds Meet Content (MIT 2017), Dan Hutto and Eric Myin claim to give a complete and gapless naturalistic account of cognition, but it comes with a kink. The kink being that content-involving cognition has special properties found nowhere else in nature, making it the case that minds capable of contentful thought differ in kind, in this key respect, from more basic minds. Contra Hutto and Myin, I argue that content-involving practices are themselves simply a further extension of action and do not therefore warrant being called 'different in kind' or 'kinky'. With the help of Ludwig Wittgenstein and John V. Canfield, I go on to challenge continuity sceptics and also suggest ways in which Enactivism meets the challenge - which Hutto and Myin say it needs to address - of explaining higher-level cognition.
\end{abstract}

$* * * * * * * * * * * * * * * * * *$

With Enactivism - particularly Dan Hutto and Eric Myin's Radical Enactivism representational content is out of the picture in basic human cognition. Does this mean that Enactivism loses its grip when it comes to higher level cognition? The problem is that the plausibility of the embodied and enactive nature of basic cognition - its being contentless, fundamentally interactive, dynamic, and relational ${ }^{2}$ - does not easily extend to forms of cognition involving language, representation, information, thought, logic, mathematics. Linguistic and mathematical capabilities constitute a challenge for the Enactivist approach because an explanation of these abilities requires us to move beyond dynamic interaction with the here-and-now environment. And so, as Hutto and Myin recognise, 'if it wants to become a full-blown alternative to representationalism, Enactivism ... has to confront [the] challenge of explaining higher-level cognition' $(2017,7)$.

In fact the problem, as I understand it, is not only one of the restricted validity of Enactivism but of its validity tout court; for, inasmuch as language and mathematics are symbolic, and therefore content-involving, the question is how they could have emerged from, and how they can interact with, the basic, contentless forms of cognition endorsed by enactivism. If there is no accounting for that, there is no place for Enactivism at all. For, what

\footnotetext{
${ }^{1}$ Professor Emeritus at the University of Toronto, Jack (as he liked to be called) was an eminent philosopher of language, philosopher of mind, Wittgenstein scholar - and a dear friend. Among his many publications are: 'The Community View (Philosophical Review, 1996); 'The rudiments of language' (Language \& Communication, 1995); 'The Passage into Language: Wittgenstein and Quine' (in The Cambridge Companion to Wittgenstein, 1996); 'Pretence and the Inner' (in The Third Wittgenstein, 2004); 'Back to the Rough Ground: Wittgenstein and ordinary language' (in Wittgenstein and Analytic Philosophy: Essays for P. M. S. Hacker, 2009); and Becoming Human: The Development of Language, Self and Self-Consciousness (Palgrave, 2007). This paper pays tribute to his deep and sensitive understanding of what it means to be(come) human.

2 'According to REC [Radical Enactive account of Cognition], the basic sorts of cognition that our brains help to make possible are fundamentally interactive, dynamic, and relational. REC's signature view is that such basic forms of cognition do not involve the picking up and processing of information that is used, reused, stored, and represented in the brain. The usual form of what REC calls basic, contentless cognition is nothing short of organisms actively engaging with selective aspects of their environment in informationally sensitive, spatiotemporally extended ways.' (2017, xiv)
} 
would be the use of positing the existence of basic cognition in humans if we can't see how it segues with our more sophisticated forms of cognition? And here, I take it, we must be able to show continuity - ontogenetically, phylogenetically and logically. The possibility for phylogenetic continuity is clearly rejected by what Doris Bar-On dubs 'continuity sceptics' according to whom:

... there can be no philosophically cogent or empirically respectable account of how human minds could emerge in a natural world populated with just nonhuman creatures of the sort we see around us. Few would deny that, biologically speaking, we 'came from' the beasts. But ... we must accept an unbridgeable gap in the natural history leading to the emergence of human minds ${ }^{3}$.... Human mental and behavioral capacities as we now know them cannot be illuminated by seeing them as elaborations on the capacities of some nonhuman ancestors. $(2013,294)$

I disagree with this position. Like Wittgenstein - whose own radical enactivism is the hallmark of his thought and broke ground for current Enactivism ${ }^{4}$ - I see language as fundamentally enactive, and the emergence of language as simply a seamless extension of action. An extension which, for generating novel or unprecedented possibilities, should not be considered incommensurable with, or different in kind from, its less sophisticated manifestations. As John Canfield writes:

We are unique on this planet, no doubt; none of our fellow creatures could understand a New Yorker cartoon, for example, or die for an abstraction like nation. But our rise to that level of sophistication does not require ... an ontological difference between us and them. $(2007,77)$

This paper strives to show that - contra continuity sceptics - there is a philosophically cogent and empirically respectable account of how human minds could emerge from nonhuman minds.

\section{Evolving Enactivism - but there's the kink}

The continuity scepticism challenge is taken up by Dan Hutto and Eric Myin in their most recent book, Evolving Enactivism: Basic Minds Meet Content (2017). Their aim is to 'provide a complete and gapless naturalistic account of cognition, right here, right now' $(2017,41)$. They claim they can do this by invoking the important, special, role played by sociocultural scaffolding. On their view, only minds that have mastered a certain, specialized kind of sociocultural practice involving public norms for the use of symbols can engage in contentinvolving thoughts and speech $(2017$, xix; 12; 134; 146). Because this enhanced cognitive repertoire appears to have occurred in full form only in the human lineage, they claim that 'minds capable of contentful thought differ in kind, in this key respect, from more basic minds'

\footnotetext{
${ }^{3}$ In fact, this - 'the claim that we must recognize a sharp discontinuity ... in the natural history of our species' is what Bar-On calls the diachronic deep-chasm claim which she distinguishes from the synchronic deep-chasm claim 'that there are deep and important differences between present-day humans and all the nonhuman animals around us' $(2013,294)$.

${ }^{4}$ For elaboration, see xxx.
} 
(2017, 134, 136; my emphasis). In acquiring the capacity for contentful cognition, the human animal does not lose its capacity for basic cognition, therefore retaining a commonality with other animals, but Hutto and Myin nevertheless take content-involving cognition to mark a distinction in kind not just between nonhuman animals and humans, but also within the human sphere $(2017,135-36)$.

This, they say, does not make their account gappy. For, the social scaffolding responsible for contentful cognition does not imply an inexplicable gap in nature $(2017,146$; see also Hutto \& Satne $(2015,510))$. What is crucial to their story about the natural origins of content, they say, is that 'biological capacities gifted by evolution could have given rise to social learning, and ... there is nothing gappy about that ${ }^{5}(2017,129)$. So that biological continuity is safeguarded; yet, they affirm, in accord with Derek Penn and colleagues (2008, 110), that: 'Darwin was mistaken: the profound biological continuity between human and nonhuman animals ${ }^{6}$ masks an equally profound functional discontinuity between the human and nonhuman mind' $(2017,134)$. So that Hutto and Myin are no continuity sceptics: they find no biological discontinuity in our acquisition of higher cognition; but they take our contentinvolving practices, because exclusive to human minds, to constitute a difference in kind between human and nonhuman minds: 'Content-involving minds have features and capacities that other, more basic minds lack: they stand apart. This difference can be thought to mark a difference in kind, not just degree, of mindedness' $(2017,134)$. They find appropriate to call this 'profound functional discontinuity' a 'kink'.

Though I agree with Hutto and Myin that 'content-involving cognition is a special achievement' (2017, 88; my emphasis), I do not agree that its purported exclusivity ${ }^{7}$ in nature warrants considering it as 'different in kind' from non-content involving cognition. As they themselves insist, the sociocultural scaffolding that have enabled the emergence of this higherlevel cognition does not imply an inexplicable gap in nature $(2017,146)$, so why attribute kinkiness to an achievement that results from a natural, seamless continuity? Why is what is only a further development not shared by others because of empirical conditions, get dubbed 'different in kind'? Why not instead think in terms of arrested development in other species, also due to empirical conditions? Hutto and Myin themselves suggest that there is no empirical obstacle to further development:

As it happens, this appears only to have occurred in full form with construction of sociocultural cognitive niches in the human lineage. ... Should creatures with basic minds manage to master such practices, they

\footnotetext{
${ }^{5}$ Their book's epigraph is: 'Natura non facit saltum' ('Nature does not make leaps').

${ }^{6}$ The continuity thesis - the idea that things change gradually, not by leaps or bangs - is explicitly maintained by many language acquisition theorists, who stand in stark opposition to Chomsky's Big Bang theory. According to Chomsky (see 1988), language suddenly appears as a kind of evolutionary accident where humans, to the exclusion of all other animals, were somehow accidentally blessed with a fully functioning prefabricated language organ. Deacon (1997) abundantly demonstrates that Chomsky's scenario is unsupported by evolutionary anthropology which evidences a gradual adaptation of the human brain and vocal chords to the use of language rather than the sudden appearance of a language organ containing a complete set of parameters enabling all grammars - Chomsky's 'Big Bang' theory.

${ }^{7}$ Though some sophisticated higher-level practices (e.g. mathematics) are exclusive to humans, it will become clear in the paper that I don't see 'content-involving cognition' as exclusive to humans.
} 
would gain new cognitive capacities and become open to new possibilities for engaging with the world and other creatures. $(2017,134)$

And indeed, as we shall see, some nonhuman animals are capable of contentful behaviour. On one hand, then, Hutto and Myin think of contentful behaviour as an exception in nature; on the other, they say our evolutionary story is continuous, and were other species to follow the human route, they would achieve the same. But if the 'kink' merely refers to a point of evolutionary development which humans alone have reached, and not anything that is empirically or conceptually impossible for other species, is it a kink? The fact that only humans have been capable of extending action to the complexity required to achieve full-blown, syntactic language does not make this extension kinky; it makes it only a further extension.

It seems to me that, in spite of endorsing biological continuity, Hutto and Myin have fallen prey to the idea that the ability to use symbols constitutes a fundamental dividing line between human and nonhuman animal $\operatorname{cognition}^{8}$ (as also between basic and nonbasic cognition). This calls to mind Terence Deacon. In The Symbolic Species, Deacon claims that for something to be called a 'language', even 'a simple language', it needs to be a form of symbolic representation; anything devoid of syntax or symbolism is merely 'a form of communication': to speak of 'animal language' is but to speak metaphorically. And so although Deacon's account of human brain and language evolution emphasizes the unbroken continuity between human and nonhuman brains, it also flags a singular discontinuity between human and nonhuman minds (1997, 13). On Deacon's view, language is the outward expression of an unusual mode of thought: symbolic representation - where 'symbolic thought does not come innately built in, but develops by internalizing the symbolic process that underlies language' $(1997,22)$. So that: 'Biologically, we are just another ape. Mentally, we are a new phylum of organisms. In these two seemingly incommensurate facts lies a conundrum that must be resolved before we have an adequate explanation of what it means to be human' $(1997,23)$. The acquisition of language is, for Deacon, 'a Rubicon that was crossed at a definite time and in a specific evolutionary context' (ibid.). But note that Deacon's definition of language as necessarily symbolic stacks the cards, and prevents gapless continuity from the get-go. The appeal of inner representations is difficult to shake off; but allowing outer representations to define language, or the human, may prove if not just as problematic, problematic enough. It seems to me that in endorsing the existence of a deep functional discontinuity or difference in kind between basic, contentless minds and nonbasic, content-involving minds, Hutto and Myin enter the representationalist camp - not less mined (and undermined) for containing external rather than internal representations.

\section{No kink to mind}

The difference in mind between man and the higher animals, great as it is, certainly is one of degree and not of kind.

-- Charles Darwin (1871) The Descent of Man

\footnotetext{
${ }^{8}$ Though in principle remaining open to animals.
} 
Hutto and Myin's kink sounds like Deacon's Rubicon. It reflects the view that divides animal forms of communication from language proper. On such a view, language essentially requires the manipulation of symbols - the possibility to go from basically expressive modes of communication to referential or representational modes of communication. For there to be a language - or for our ancestors to have crossed this Rubicon - they had to have mastered the ability to use sounds that hooked up with referents by representing them. This is a view which, it seems to me, ought not to be endorsed by Enactivism of any kind. It certainly doesn't square with Wittgenstein's enactivism.

For Wittgenstein, language is essentially linked to use, be it representational or otherwise. What gives our gestures or words meaning is their use - whether that use be as expressive as 'Ouch' when punched in the stomach or as symbolic as Caesar's thumb down for the poor bloke in the arena. And of course, use has all to do with our language-games and our forms of life. In the same way that 'the appeal to the inner as grounding or providing a fullblown 'referential' language must be rejected' (Canfield 2007, 34), so too must the view of referential language as something that transcends or goes beyond the scope of action be rejected. Rather, we must view 'language tout court [as] a set of customs in which words play a role' (2007, 34); language, that is, is nothing but 'custom-regulated action' $(2007,35)$.

As Wittgenstein shows, language is inherently enactive. This is not to say that there is no categorial difference between the concepts of language and action, but that the boundary between the two is porous. The passage - be it phylogenetic or ontogenetic - from contentless to content-involving cognition, in sometimes involving language, does not involve something that is incommensurably different from action or behaviour. Not all action is linguistic, but language is fundamentally - that is, phylogenetically, ontogenetically and, indeed, logically, linked to action. This is obvious enough to see in animal languages, but the human use of language - as Wittgenstein has made clear - is nothing but the mastery of a technique, a knowhow. However sophisticated the mastery may become - however sophisticated the symbols it involves - it remains a mastery; a matter of know-how, not of knowing that. Enactivism is not dislodged by the use of symbols, however complex. Hutto and Myin agree with this: 'Even when cognition involves content and inferential processes, the ultimate character of cognition remains enactive and dynamic $(2017,91)$. But then why insist that 'if it wants to become a fullblown alternative to representationalism, Enactivism ... has to confront [the] challenge of explaining higher-level cognition' $(2017,7)$ ? The putative worry, mentioned at the beginning of this paper, is that content is not enactive-friendly in that it goes beyond action - 'beyond interaction with the here-and-now environment' - and is therefore incommensurable with animal or basic cognition. But is an animal's wooing call not just as distant from the here-andnow environment as Marvell's 'To His Coy Mistress'? Is one not simply a more sophisticated call than the other - and so manifests a difference in degree, not in kind? There is as much anticipation, desire, hope, and sometimes even deceit, in the courtship calls of some animals as there are in those of humans. Take the fall field cricket; its less desirable smaller males produce courtship calls that dishonestly signal the body size of high condition males in order to be more sexually attractive (Harrison et al 2013).

This example of animal interaction beyond the here-and-now environment also indicates that animals are capable of false representation. But this crosses Hutto and Myin's dividing line between animal and human cognition. For, on their view, forms of cognition are 
content-involving in that 'they represent the world in ways that can be true or false, accurate or inaccurate, and so on' (2017, xii), and this is thought to be a kinky departure from animal cognition. But is it? If animals are capable of deceit and the manipulation of attention and evidence, then according to Hutto and Myin's definition of content, there is room for content in animal communication and social practices. And of course the fall cricket is far from the only animal capable of deceit. As Whiten and Byrne (1988) have shown, all groups of monkeys and apes use deception, though the insight necessary to plan or understand deception seems restricted to great apes (Byrne 1995, 203). Examples of deception include: leading other animals towards or away from places; making them think that the agent has been hurt; concealing the excited glances that would reveal a hidden food, or concealing the food itself in the hand or under the body.

So misrepresentation does not require the use of symbols. Indeed, prelinguistic children often misrepresent their feelings and behaviour - sometimes concealing the latter, and exaggerating the former by forced crying. But nor is the use of symbols exclusive to humans. And by this, I don't only mean the use of symbols that humans have taught animals ${ }^{9}$, but the naturally-occurring arbitrary relationships between signified and signifier in some animal communication. A celebrated example being that of vervet monkeys (Seyfarth \& Cheney, 1990, 1996) who have been shown to use a 'bark', a 'cough' or a 'chutter' to communicate the presence, respectively, of a leopard, an eagle, or a snake ${ }^{10}$. As linguist James Hurford writes:

There is nothing (as far as we know) inherently leopard-like in a bark, or inherently bark-like in a leopard. It seems more reasonable to grant that the vervets are using genuinely arbitrary symbols, than to assume that vervets perceive the world in ways radically different from our own, so that for them the relationships here are somehow iconic or causal. So some arbitrary symbolic behaviour can be found in nature. And in fact such very limited arbitrary symbol systems can be seen in many species, especially in their alarm calls. There is a vast difference in degree between the inventories of arbitrary symbols used by animals (up to about thirty distinct calls used by wild chimpanzees) and the vocabularies of human languages, which contain many tens of thousands of items. (2004, 553-54; my emphasis)

And Hurford also argues that 'recursive thought could have existed in prelinguistic hominids, and that the key step to language was the innovative disposition to learn massive numbers of arbitrary symbols' (2004, abstract). If the human use of symbols differs from some uses of animal vocalisations and gestures only in quantity and degree or quality, the difference

\footnotetext{
${ }^{9}$ It is a 'well-known fact that animals are able to learn small sets of arbitrary signal-meaning relationships. The most celebrated trained apes, Kanzi (Savage-Rumbaugh and Lewin, 1994) and Nim (Terrace, 1987), have been able to acquire arbitrary symbolic vocabularies of several hundred items' (Hurford 2004, 554-55).

${ }^{10}$ Bruce Richman (1976) found that gelada monkeys can produce sounds hitherto thought to be exclusive to human speech, such as vowel and consonant sounds and sounds articulated in different parts of the vocal tract such as labials and dentals. Richman (1987) also notes that the gelada's highly synchronised exchanges of contact calls share many of the rhythmic and melodic properties of human speech patterns (see also Richman 1978), and relates this to the need to resolve emotional conflicts inherent in many social situations.
} 
- Darwin was right to say - is not one of kind. As Hurford adds: 'even qualitatively new features have precursors - they don't just come from nowhere' $(2004,2)$.

The kinds of practices enabling the emergence of symbols are continuous with those that are not thus enabling. That the products of those practices; what our practices enable - be they the wheel, spaceships or mathematics - are unprecedented in our evolution and (still) exclusive to human minds does not (pace continuity sceptics) cause a gap in the continuity of that evolution, and (pace Hutto and Myin) warrant regarding them as constituting a functional kink in that evolution. It is inasmuch as our practices are gradual and continuous that no gap is created, regardless of the novelty (or kinkiness) of what they enable.

Note that Hutto and Myin do find their own continuity story gappy in one respect: 'it can't fill in all the relevant details' $(2017,140)$. So I will now try - with the help of Wittgenstein and Canfield - to fill in some of those details.

\section{Wittgenstein's Enactivism}

One of the important things Wittgenstein said about language, and indeed meaning, is that it has its root in gesture - 'What we call meaning must be connected with the primitive language of gestures' (2005, BT 24) - or , as he also put it, language is rooted in 'action', and more precisely: 'reaction' or 'instinct':

The origin and the primitive form of the language game is a reaction; only from this can more complicated forms develop.

Language - I want to say - is a refinement. 'In the beginning was the deed.' (1993, CE 395)

Language, then, is a refinement, or 'an extension', of our primitive behaviour:

Believing that someone is in pain, doubting whether he is, are so many natural kinds of behaviour towards other human beings; and our language is but an auxiliary to and extension of this behaviour. I mean: our language is an extension of the more primitive behaviour. (For our language-game is a piece of behaviour.) (1980a, RPP I, 151)

He makes this clear in On Certainty:

I want to regard man here as an animal; as a primitive being to which one grants instinct but not ratiocination. As a creature in a primitive state. Any logic good enough for a primitive means of communication needs no apology from us. Language did not emerge from some kind of ratiocination. (1977, OC 475)

That we can use reason does not mean that language emerged from the use of reason, or is dependent on reason. The very same 'logic' - or grammar - responsible for primitive language is responsible for ours. Wittgenstein conceives of language as rooted in our primitive actions and interactions - not in reason, and not in symbols.

Language, for him, is an extension of our primitive behaviour; it emerges from the development of some of our animal or natural reactions. Not just any natural reaction - not singular or idiosyncratic ones, like tics - but our shared natural reactions; what Wittgenstein 
calls 'the common behaviour of mankind' (1997, PI 206): reactions such as crying when in pain or sad; smiling when glad; jumping when startled; gasping or screaming when afraid; reacting to someone's suffering. These instinctive common reactions or action patterns are, Wittgenstein says, the prototypes of our modes of thought (1980a, RPP I, 916); of our concepts. Without these behavioural patterns, there would be no language. These are the starting-points of language: 'it is characteristic of our language that the foundation on which it grows consists in steady ways of living, regular ways of acting' (1993, CE 397; my emphasis). Our acquiring concepts, such as pain, requires that we have appropriate, i.e. normal, human reactions: 'If a child looked radiant when it was hurt, and shrieked for no apparent reason, one couldn't teach him to use the word "pain"' (1988, LPP 37).

So how is the child trained to go from proto-language games - that is, from her instinctive reactions - to language? How, for example, asks Wittgenstein, does a child learn the meaning of the word 'pain'? And he replies:

Here is one possibility: words are connected with the primitive, the natural, expressions of the sensation and used in their place. A child has hurt himself and he cries; and then adults talk to him and teach him exclamations and, later, sentences. They teach the child new painbehaviour. (1997, PI 244)

So the connection between the name and the thing is not made by an act of ostension, not by merely hooking gestures on to their public referents, but by contextualized repetition in practice. As psychologist Derek Montgomery observes, if the carer repeatedly uses the verb 'want' while interpreting the infant's behaviour in certain contexts, it is 'reasonable to suspect that when the verb emerges in the child's lexicon it will be in familiar contexts such as [those] where the child has repeatedly heard it being used. The meaning of the term, like the meaning of the prelinguistic gesturing, is bound up in the role it plays within such contexts' $(2002,372)$.

Note: what Wittgenstein says the child is taught in learning to replace his primitive reactions with words is new behaviour; that is, in first picking up the linguistic expression, the child is not describing with it or referring with it, but still reacting with it.

\section{Canfield's elaboration: ontogeny}

Wittgenstein's view that language is an extension of action is often mentioned, but not often fleshed out. John Canfield remedies this in his book: Becoming Human (2007). In keeping with Wittgenstein's prescription: 'Don't think, but look', Canfield writes: 'To see what language is, examine - observe - language-games. To do that, begin by observing the simplest ones the child comes to master' $(1995,197)$. Canfield did just that out of his philosopher's armchair, by keeping a diary of his daughter Zoe's acquisition of language.

Canfield draws a threefold classification of language or language-related phenomena which he finds implicit in what he calls Wittgenstein's 'philosophical anthropology'. These are:

(1) 'proto language-game'

(2) 'gestural stage' and

(3) 'primitive language-game 
His observation begins at the bedrock level of the development of language, constituted by the naturally-occurring pre-symbolic interaction patterns - which, as noted earlier, Wittgenstein calls the prototypes of our modes of thought (1980a, RPP I, 916). Canfield calls them proto language-games. They include nursing, giving things to the child, cleaning, dressing, hugging, responding to cries, playful two-person dealings such as tickling, or passing an object back and forth, accompanied by eye contact ${ }^{11}$. We are not yet here in the realm of language: the proto language-game precedes even the simplest use of symbols and gestures remembering that a gesture is an intentional movement: 'a movement of part of the body, especially a hand or the head, to express an idea, meaning or feeling' (Cambridge Dictionary). The child is engaged in behaviour patterns basic to language; she is not using language:

Both the before-language hominid and the pre-linguistic child engage naturally in certain behaviour patterns basic to speech. As regards the child, consider the acts and responses connected with request words. At the earliest stage the child simply cries when hungry, or cold, or wet, and so on. Then the mother responds, say by bringing it to her breast, whereupon the child does its part by suckling. Similarly, there is the interaction pattern of the child's reaching toward something, and the mother's response of handing it to the child. Such interactions arise naturally, without any drill or explicit instruction, between child and caretaker. They support the development of language, which could not arise without them. $(2007,37)$

Such interaction patterns - found in many animals - are rooted in our animal nature, in particular in our ability to anticipate and respond to one another's actions.

The next stage to language is through gesture. When a proto language-game is modified, emphasized, or added to, in a way that brings it to the other's attention, it becomes what Canfield calls 'a natural gesture'. An example is when an infant turns an action - such as instinctively raising its arms when being picked up - into a gesture, by performing it in the absence of being picked up; that is, in the absence of the interactive behaviours normally preceding it. Franz Plooij speaks here of 'the development by human infants of an arm-raising gesture which at first appears in the infant's repertoire as a passive response to being picked up and later becomes an active request to be picked up' (1978, 117; my emphasis). And he finds this very same development occurring in primates:

In order to groom [the infant's] side and armpits, [the chimpanzee mother] takes his arm and pulls it upwards. [Later] the infant ... adopt[s] this posture unaided while his mother grooms him.... At the age of 11 months an infant... came up to his mother, sat down in front of her and adopted this posture.... Almost predictably, his mother groomed him. (ibid.)

\footnotetext{
${ }^{11}$ For a related, perhaps complementary, set of sufficient, general holding conditions at the basis of language, see Gallagher: 'With exceptions for pathological cases, we arrive on the scene already attuned to other people's faces and their emotional expressions; we come already perceptually attentive to biological motion; we come already prepared for embodied interaction with others - and we are immediately pulled into such processes by caregivers and other persons.' (2012, 208). I see these -- which Gallagher proposes as 'social interaction processes of primary intersubjectivity' that get 'social cognition off the ground' -- as more of the pre-symbolic interaction conditions or necessary starting-points of language.
} 
Canfield calls these 'natural gestures' in that he sees them as biologically based, arising naturally, without being taught.

Another example of a spontaneous action developing into a natural gesture is a child reaching toward something it wants but can't get, and so makes an opening and closing motion with her outstretched hand. The mother's responding to the child by giving her the thing she wants will eventually lead to the child adopting that motion to deliberately 'ask' for what she wants. In both examples, the gestures function like signals; they constitute communicative acts: 'We would, I believe, have no trouble in saying that the child making the hand opening and closing gesture is communicating with its mother. The distance between that gesture and speech per se is small', writes Canfield $(2007,39)$.

Such 'natural gestures' are a stylized overlay upon the prior, naturally-existing interaction pattern. The third stage comprises the further stylization made when simple or oneword language-games develop from the proto-type or its gestural embellishment. This is the scenario sketched by Wittgenstein in PI 244: the child learns the meaning of the word 'pain' when it is connected by an adult to a natural expression of pain. We must beware not to think of this last stage as a mere nominalisation process. The child's using the word 'up' doesn't result from a mere ostensive teaching of words, but from exposure to and habituation in a form of life. For the child to use the word 'up', it had to have been exposed to a variety of 'languagegames', where the utterance of the word 'up' is interwoven with action - the child is lifted and lowered to the accompaniment of 'up we go ... down we go'; a bird is pointed to as being 'up on the tree'; she hears that her teddy bear is in her room 'upstairs' etc. Here, words, behaviour, and context repeatedly and variously interact to inculcate in the child her native language. Wittgenstein's lesson is that language should be understood as the mastery, not of a calculus or principles, but of complex interlocking language-games.

In the simple language-game, the word replaces the gesture and takes over its function: telling the mother what the child wants. The child - having been previously coached - might say: 'up' instead of gesturing with a look. The word / symbol is a more sophisticated development of the gesture in that its relationship to its function is purely conventional and arbitrary. Any other short and easily pronounceable word would have served the same purpose. We can see that it is a very small step - and not a leap - that the child takes from gesture into word-language; and far from evincing a 'profound functional discontinuity' between basic and nonbasic cognition or between animal and human cognition, it shows functional continuity: the word, or other symbol, replaces the gesture and takes over its function. As Stephen Cowley, glossing Canfield's Wittgensteinian account, notes: 'resembling as it does the gestural expression of pre-linguistic games, there is no deep puzzle about this new word-language' (2007, 279). I will let Canfield summarize:

In being able to speak its intention the child manifests two linked abilities. The first is one shared with any number of animals - it is to evince the behaviour we call acting with an aim. It is to pursue a project. The second ability is, it seems, unique to humans, at least if we restrict the claim to animals in the wild. It is to speak a word or otherwise provide a symboltoken that indicates the end point of the project the person is in fact engaged upon. 
While this later ability is (with the earlier qualification) unique, it is but a small embellishment of a capability which is not unique - the talent of indicating one's project by a natural gesture. The passage to speech does not cross some great ontological divide; there is no fundamental difference between us and other animals. In fact, captive chimpanzees can learn to 'express their intentions' in symbols. Here Wittgenstein, as opposed say to Chomsky, is a Darwinian. $(2007,41)$

\section{Grammar: enactive and embedded}

To understand a language means to be master of a technique.

-- Wittgenstein (PI 199)

What is important to note is that, in mastering different language-games - such as those involving the word 'up' - the child is mastering the grammar of the word; its use in the language. Wittgenstein's notion of grammar is not more complicated than this. Rules of grammar are simply expressions of the norms of sense that are socially generated and maintained; they grow out of, and with, our natural ways of acting and our socio-cultural practices. Grammar does not generate language; nor does it exist independently of language or action; it is embedded and enacted in what we say and do. The proper use of the word 'up' is manifested in our ways of acting and speaking. The child assimilates these norms as it assimilates the language - through guidance in and exposure to, correct usage. As Peter Hacker puts it: 'Rules for the use of words are exhibited in human discourse, in explanations of meaning, in corrections of errors, in what counts as accepted usage' $(2010,29)$. And the same can be said of numbers: 'Our children - writes Wittgenstein - are not only given practice in calculation but are also trained to adopt a particular attitude towards a mistake in calculating ${ }^{12}$ [variant: '... towards a departure from the norm']' (RFM VII 61, p. 425) - that is, children are habituated into standards of correctness of the practice in question, and thereby formed to act and react in particular ways; they are thus trained to master a technique through the inculcation of a normative attitude.

The assimilation of rules - be they linguistic or mathematical - does not have the features of a learning that, but of a learning how - of a training or a conditioning. As varied as they may be, rules are assimilated with the aim of gaining a technique, a skill, a method, a way of acting (or refraining from acting, as in rules of social etiquette or games). Wittgenstein:

A rule is best described as being like a garden path in which you are trained to walk, and which is convenient. You are taught arithmetic by a process of training, and this becomes one of the paths in which you walk. (2001, AWL 155)

Calculating, using mathematical rules, are mechanical activities; like making moves that one was trained to perform. Wittgenstein compares rules of mathematics to orders or commands (1978, RFM VII 40; V 13): 'The mathematical proposition says to me: Proceed like this!' (1978,

\footnotetext{
12 'This is how calculation is done, in such circumstances a calculation is treated as absolutely reliable, as certainly correct' (1977, OC 39); 'This is how one calculates. Calculating is this. What we learn at school, for example. Forget this transcendent certainty, which is connected with your concept of spirit' (1977, OC 47).
} 
RFM VII 73); 'it determines ... lays down a path for us' (1978, RFM IV 8). We do not come to a rule from reasoning, we accept a rule blindly (provided we want to play the game):

When I obey a rule, I do not choose.

I obey the rule blindly. (PI 219)

For Wittgenstein, 'the centre of gravity' of our mathematics lies 'entirely in doing' (1978, RFM IV 15). Equations are, like rules essentially enactive: to formulate an equation, say ' $2+2=4$ ', has, in heuristic contexts, the status of a deed, parallel to directing a child's first steps with one's hands; at other times, it is to perform an operation. And to follow a rule can be like reacting to a push. To follow a rule is not to make a judgment, but to make a move. Indeed, in the Remarks on the Foundations of Mathematics, Wittgenstein considers the dispensability of propositions in arithmetic, stressing the similarity of calculating to gestures, and of the teaching of arithmetic to a training:

Might we not do arithmetic without having the idea of uttering arithmetical propositions, and without ever having been struck by the similarity between a multiplication and a proposition?

Should we not shake our heads, though, when someone shewed us a multiplication done wrong, as we do when someone tells us it is raining, if it is not raining? - Yes; and here is a point of connection. But we also make gestures to stop our dog, e.g. when he behaves as we do not wish.

We are used to saying ' 2 times 2 is 4 ', and the verb 'is' makes this into a proposition, and apparently establishes a close kinship with everything that we call a 'proposition'. Whereas it is a matter only of a very superficial relationship. (1978, RFM III 4)

It should now be clear that Wittgenstein's account of the emergence and practice of language and mathematics is an enactive account. Language is simply an extension of an underlying action pattern, a way of acting; and we come to extend the scope of our ways of acting through grammar - that is, through a normatively generated and sanctioned use of words or symbols. The generating, sanctioning, transmitting, and understanding of these symbols are all logically due to, or embedded in, action; that is, they are inherently enactive. The transmission of language is the transmission of an extension of action; of new ways of acting. Wittgenstein rightly stresses that in teaching a child to replace the natural expression of pain with the word 'pain', adults teach the child 'new pain-behaviour' (1997, PI 244; my emphasis); that is, they also teach the child a new way of acting, a skill. For, grasping a concept is not a matter of connecting a referent to a public symbol, but of acquiring a skill. It is thanks to her acquiring this skill, this normative attitude, that the child is eventually able to go on, on her own; to proceed from other-regulation to self-regulation (Medina 2002, 165). Successful enculturation means the child can judge for herself that in a particular instance a word or phrase makes sense, not by comparing it to a benchmark, context-free, use but on the basis of her experience of multiple language-games in which the word or phrase is employed.

\section{Content is not an inner growth}


Language grows in sophistication, not because of some language of thought that craves expression, but in tandem with the sophistication of our socio-cultural practices or customs. It isn't, as Lawrence Shapiro would have it, that 'language or its symbols acquire their meaning from meaningful thoughts-how could it be otherwise?' $(2014,217)$ - but rather that meaningful language or thought acquires its meaning from use - both synchronically and diachronically speaking. Synchronically, the meaning of a word or sentence is determined by its use or the context in which it is uttered; diachronically, meaning is conditioned by our 'ways of acting' and 'very general facts of nature'. As Wittgenstein writes: 'it is characteristic of our language that the foundation on which it grows consists in steady ways of living, regular ways of acting' (1993, CE p. 397). That is to say: the very grammar of our language is conditioned by our ways of living. This is what I call the reality-soaked nature of grammar and concepts ${ }^{13}$.

So, for example, the term (or concept) 'daughterliness' as loving attention to the integrity of the daughter-parent relationship, as also our acquisition of that term - are conditioned by, and embedded in, our forms of life, ways of acting, instinctive behaviour etc. We could not learn the proper use of that term without experiencing or at least being exposed to practices in which terms like 'daughter' 'father' 'mother' are used in the context of loving attention, respect etc. to individuals immediately related by blood or adoption. That is, we can't acquire the meaning of such a term as 'daughterliness' other than through some exposure to, or experience of, the phenomena that can give rise to such a term. We come to know what kinds of behaviour constitute or qualify as daughterly for having learned the term 'daughterly' by experiencing or otherwise being exposed to such behaviours.

So that what the adult does when teaching a child to replace the gesture with a word is, as Stephen Cowley nicely puts it, enable the child 'to align its behaviour with the grammar of [the word]', to 'attune to a bundle of local customs' (2007, 293). Once it is clear that words are symbols - that is, functionally-continuous replacements for ways of acting and communicating that are embedded in these ways of acting, symbols cease to appear unnatural or unaccountably alien to our natural practices. To speak as do Hutto and Myin of 'the emergence of a special sort of normative sociocultural practice involving the use of public symbols' $(2017,146)$ is not to encounter a kink in our practices, but a natural and enactive extension of our practices.

Stepping into language is not a crossing into a brave new world, where suddenly, because the word (sometimes) replaces the deed, concepts have become incommensurable with our actions. Yes, our tools are more sophisticated than those of primates but they evolve from those, without a kink. Wittgenstein has no trouble tracing some of our concepts back to the apes, as in this passage:

An ape who tears apart a cigarette, for example. We don't see an intelligent dog do such things. The mere act of turning an object all around and looking it over is a primitive root of doubt. (1980b, RPP II, 345) ${ }^{14}$.

\footnotetext{
${ }^{13}$ Their being conditioned by facts that unassailably pertain to the human form of life makes some of our rules of grammar universal - that is, they are the bounds of sense from which any normal human being must begin to make sense. Alongside these, more local grammars emerge from the different forms of human life. See xxx. ${ }^{14}$ This passage provides an apt illustration of Doris Bar-On's suggestion that 'our commonsense descriptions of the expressive behavior we share with existing nonhuman animals - as well as those provided by ethologists -
} 
As for mathematics, it is, he writes, 'an anthropological phenomenon' (RFM p. 399).

\title{
7. Ontogeny recapitulates phylogeny
}

\author{
We are just animals, part of the natural world; \\ clever ones that can be raised to a mastery of a whole \\ complex of human customs - human ways of \\ interacting including the deployment of words. But \\ animals none the less. \\ -- John Canfield $(2007,77)$
}

Canfield concedes that there is nothing new in the idea that speech grows from an earlier stage of gesture. What is new about the Wittgensteinian view he and I defend is the idea that there is no categorial difference between gestural and verbal communication, and that symbolic communication is not exclusive to either ${ }^{15}$. As Canfield succinctly puts it: 'Language is a set of customs in which words play a role' $(2007,70)$. The difference between our ancestors and other primates seems to be that only the former were able to further develop their communicative abilities from the rudimentary social life they shared with other primates. Why the development went further in the human case and not that of the chimpanzee is empirically a question for anthropology and primatology, but the philosopher too can offer answers. Canfield suggests that for material culture and societal organization to have influenced the development of language-customs

... [the] use of words must have had a point, and in the life of wild chimpanzees, where food is possessed only as long as it takes to eat it, and where tools are normally discarded after use, there is no, or extremely little, room for there to be such a point. But with the development of prized articles of material culture, and a societal practice that amounts to the honouring of ownership, a proto-language game of possession can emerge, and there may develop associated natural gestures, such as seizing back some object. ... There would then be scope for the emergence of a word which, by replacing such a gesture, in such a context, makes a claim of possession, as opposed to simply taking [back]. ... It is easy to imagine how the mastery of various language-games could have facilitated cooperation among our hunter-gatherer ancestors. (2007, 72-73; my emphasis)

This, at first blush, seems very close to Michael Tomasello, on whose account the evolution of intentionality into human-specific forms was due to the need for cooperation: 'Human beings ... are all about (or mostly about) cooperation. Human social life is much more cooperatively organized than that of other primates, and so ... it was these more complex forms of cooperative sociality that acted as the selective pressures that transformed great ape individual intentionality and thinking into human shared intentionality and thinking' (Tomasello 2014,

can guide us towards a natural intermediate stage in a diachronic path connecting the completely unminded parts of the animal world with the fully minded, linguistically infused parts that we humans now occupy' $(2013,39)$.

${ }^{15}$ See Xxx. 
31). There is, however an added twist to Tomasello's account: it is poised on Theory of Mind: the ability to ascribe unobservable mental states to others. This ability is called a 'theory' in that mental states are (allegedly) inherently unobservable, and so the rightness of our ascriptions can never be verified; it can only be inferred. As Wittgenstein and Merleau-Ponty have argued: this theoretical presumption imposed on the possibility of intersubjective understanding is both superfluous and misleading ${ }^{16}$. Intersubjective understanding is wrongly taken to depend on 'mindreading', particularly as embodied and extended capabilities are sufficient to sustain social understanding and interaction ${ }^{17}$ - or what John Michael calls 'interactionism' $(2011,560)$. And if mindreading is not what basically enables humans to interact with, and understand, one another, it should certainly not be pinned on our nonhuman ancestors ${ }^{18}$.

Even as he affirms the importance of interaction and sociality for the transformation of individual into human-shared intentionality, Tomasello takes these to rely on individual metarepresentations of others' mental states (2014: 94). It is here that - having gone a long way with Wittgenstein - he parts company with him: having advocated the enactive genesis of language, Tomasello cannot resist a complementary appeal to 'theory of mind'19. But the mentalist / representationalist seduction - rooted, at best, in a superfluous, unsubstantiated metaphysical assumption - must be resisted.

Not an easy task. Louise Barrett describes the kind of 'backward reasoning' that drives current evolutionary theory when it comes to phylogenetic language acquisition: it is assumed that 'language has to arise from a mentalizing mind (rather than certain aspects of the human mind being a consequence of language)'; that 'a certain kind of mindedness ['Theorymindedness'] must be in place prior to language so that we can get to the forms of linguistic communication that are used to define our own species' $(2018,10-11)$. The possession of ToM goes hand in hand with the indexing of social intelligence to brain size - and more specifically to an enlarged neocortex size, taken to focus principally on the ability to 'use knowledge about other individuals' behaviour - and perhaps mind-states - to predict and manipulate those individuals' behaviour' (Dunbar (2003), 167). As Barrett concludes: '... the ToM paradigm ... drives much of the social intelligence/brain hypothesis' $(2018,13)$, so that '[w]e do not begin with 'man as an animal', in Wittgenstein's words, but with a particular scientific construction of human mindedness, which we then extend far back into the evolutionary past', 'generating an overly intellectual view of what it means to be a competent and successful social primate' $(2018,10 ; 2)$. This retrospective attribution of ToM to our ancestors as, allegedly, the only way

\footnotetext{
16 There is no space here to rehearse the argument, amply made by Wittgenstein and Merleau-Ponty, that other minds are not, by default, hidden to us. See inter alia xxx, McGinn (1998), Gallagher (2012), Zahavi \& Satne (2016).

${ }^{17}$ As psychologist Richard Gipps summarizes: 'In place of ... an intellectualist, disengaged, cognition-focused psychology, we are offered perspectives that stress the primitive foundational character of our prereflective (noncognitive) engagement with one another, our emotion, our expression, and our embodiment' (2004, 195).

${ }^{18}$ See especially Tomasello (2016), but also Tomasello et al (2016): That great apes operate, at least on an implicit level, with an understanding of false beliefs suggests that this essential TOM skill is likely at least as old as humans' last common ancestor with the other apes' (p. 113). But Tomasello is not alone; see Jill Byrnit's Primate Theory of Mind: a state-of-the-art review. Journal of Anthropological Psychology 17:2006, 1-21.

${ }^{19}$ In philosophy, a similar position is adopted by Michael (2011) who claims that interaction complements, and may even contribute to mindreading, but does not replace, and Kim Sterelny who similarly defends a gestural origins hypothesis while hanging on to a complementary representationalist Theory of Mind (e.g., Sterelny 2012).
} 
to justify the complexity that comes with social bonding and successful cooperation is profoundly amiss, for ToM should not even be applied to humans ${ }^{20}$. I suggest, however, that once rid of its ToM component, much good can be drawn from a hypothesis that puts social pressure and social intelligence at the helm of phylogenetic language acquisition. It's important that we retain the Bonding Theory when we get rid of the misleading ToM imposition.

And here I think Robin Dunbar's (1993) theory of 'vocal grooming' replacing manual grooming deserves renewed attention. It offers a plausible, thoroughly enactive-friendly, account of the evolutionary emergence of verbal language, which echoes Canfield's and Tomasello's emphasis on cooperation without importing the mentalistic picture ${ }^{21}$. Starting from the generally-accepted view that the cohesion of primate groups is maintained by social grooming, Dunbar argues that, as group size increased in nonhuman primates, social cohesion could no longer be achieved through the usual manual grooming. Because it freed the hands and allowed for simultaneous foraging and other activities, and for multiple partners to be groomed at once, vocalisations or 'vocal grooming' came to replace $\mathrm{it}^{22}$. And so language evolved as a more efficient form of social grooming, 'enabling ancestral humans to maintain the cohesion of the unusually large groups demanded by the particular conditions they faced at the time ${ }^{13}$ (1993, 11). Dunbar sees human language as continuous with primate vocal communication, viewing 'the contact-calls used in many species of anthropoid primates as possible natural precursors for human language: 'Although these calls have traditionally been interpreted for maintaining contact during movement (hence their generic name), it has become clear that there may be more subtle layers of meaning to [them]' - as for example, vervet monkeys using them 'to comment on events or situations as they occur'. He considers the vocal signalling of vervet monkeys as an 'archetypal protolanguage', already incipiently speech-like. In his view, these monkeys are almost speaking when they emit 'quite arbitrary' sounds in referring to 'specific objects' (1996, 140). In fact, Dunbar suggests that grammar was present long before human language, being central to primate cognition including social intelligence. An objection made to Dunbar is that he has not addressed the problem of how 'meanings' came

\footnotetext{
${ }^{20}$ We do not normally theorize about whether other human beings have mental states (and only in some cases do we even ask ourselves what our interlocutor is really thinking or feeling). Our 'certainty' about someone having a mind is not an implicit conclusion we come to, but an instinctive, nonepistemic attitude; not resulting from inference, it is not open to falsity or mistake. It may be open to pathological failure, but then this is only the exception that confirms the rule. See xxx. Wittgenstein rightly rejects the notion that we can never really be certain of what another thinks or feels, so it is spurious to attribute to us a Theory of Mind: 'But of course it isn't true that we are never certain about the mental processes in someone else. In countless cases we are' (1992, LW II, 94); 'It is only in particular cases that the inner is hidden from me; and in those cases it is not hidden because it is the inner' (1992, LW II, 33). Indeed, in many cases where a feeling or thought is explicitly manifested, it may not be a genuine feeling or thought.

${ }^{21}$ Dunbar imports the mentalistic picture elsewhere (e.g., Dunbar (2009), 568), but it is sufficiently absent in this paper to offer a clearly enactive hypothesis.

${ }^{22}$ Dunbar suggests that the switch from manual to vocal grooming began with the appearance of Homo erectus, around two million years ago $(1996,115)$.

${ }^{23}$ It is - to use the terminology used by Dunbar on his website - one of many 'cognitive tricks' used to overcome the constraints that time places on an individual's ability to manage their relationships. Dunbar notes that this explanation stands in direct contrast to the conventional wisdom that language developed, and brain size increased, in the context of hunting communication and tool-making development. In fact, 'the markedly improved tool designs of the Upper Palaeolithic can ... be better interpreted as a consequence rather than a cause of enlarged brain size' $(1993,15)$.
} 
to be attached to previously content-free vocalisations ${ }^{24}$, but I would say that meaning was there all along (and, with it, grammar ${ }^{25}$ ) - it just didn't come in propositional form. And nor does it need to. As Wittgenstein has argued, meaning is not always propositional or truthconditional. For example, what Wittgenstein calls 'spontaneous utterances' - spontaneous firstperson present tense psychological expressions (e.g. 'I'm afraid', 'I hope he comes', 'I'm in pain') are non-descriptive, nonepistemic expressions, akin to behaviour ${ }^{26}$.

We can view the passage from 'manual grooming' to 'vocal grooming' as the phylogenetic equivalent of the child's stepping from gesture into word. In both cases, the move seems functionally continuous. The use of words and symbols is a naturally coherent move to increase efficiency, proficiency, flexibility and density of expression and communication. The economy and manipulability of verbal language is such that it can rise to a level of sophistication of meaning that gesture alone could not reach, but as Wittgenstein reminds us, meaning is intrinsically connected to the primitive language of gestures (2005, BT 24).

\section{Conclusion}

Given a Wittgensteinian account of the nature of language and its possible origins, it is not necessary to posit some representational gap or leap between nonhuman and human primates, or a content-involving kink demarking humans from the rest. The latter gives fodder to the view that explaining higher-level cognition is a challenge for Enactivism; but I hope to have shown that it isn't really. As to the former (continuity sceptics), accounts of the circumstances that enabled the move of some animals into word-language may be speculative, but those that consist in the postulation of ad hoc properties or entities such as inner representation systems or a language organ should, I suggest, come last and not first in the list of our plausible accounts. Where there is a simple, plausible story that will do, why - in the name of science or philosophy - convolute it? I hope to have at least made more plausible that, pace continuity sceptics, 'human mental and behavioral capacities as we now know them' can, indeed, 'be illuminated by seeing them as elaborations on the capacities of some nonhuman ancestors' (Bar On, 2013). I don't see that the use of public symbols marks a gap between basic, contentless cognition and content-involving cognition, or even a 'challenge' that an enactivist account must face in explaining higher-level cognition (Hutto \& Myin 2017, 7). As Canfield writes:

Our language has grown from a stage of primitive gesture communication found in many animals to full-fledged modern speech. There is now a difference of quality between our mode of communication and that of the other animals. But this difference of quality can be seen as arising from a difference in quantity. New language-games appear; old ones are refined

\footnotetext{
${ }^{24}$ He sees this development as a 'small step' (1996, 141). Dunbar notes that Cheney \& Seyfarth (1982) have shown that slight differences in the acoustical form of the calls allow the audience to infer a great deal about the event or situation on which the caller is commenting, even in the complete absence of any visual information' (Dunbar 1993, 17; my emphasis). Of course, I disagree that what is being understood here is so as a result of inference.

${ }^{25}$ In the broader, Wittgensteinian, sense of grammar: as the often unarticulated, customary rules that govern our use of words and, by extension, our intentional actions (gestures) or nonverbal vocalisations.

${ }^{26}$ For more on this, see $\mathrm{xxx}$
} 
and added to in various ways; speech customs proliferate and evolve. But in all this we do not supersede our basic animal nature. $(2007,77)$

The sophistication our language is capable of should not obfuscate its relatedness to its animal origins. It has been shown that most of what we believed set us apart from animals does not - animals have language; they use tools; they use symbols; they even share our Machiavellian intelligence; and - inasmuch as culture is defined as behaviour that is socially transmitted - they have culture: they cooperate and teach each other things. So if language, symbols, cooperation, tools, deceit, and culture are not unique to humans, where's the kink? In the ability to look forward, suggest Seligman and Tierney in their book Homo Prospectus (2016). Only we, human prospectus, can anticipate what fellow humans will do in the distant future. Seligman and Tierney attribute this feature to our brain, but I would attribute it simply to the sophistication of our language - which explains why, as Wittgenstein noted, a dog can believe his master is at the door, but it can't believe his master will come home the day after to-morrow ${ }^{27}$. Dogs can anticipate alright; they can pine for the return of their master in the future; and sit in expectation at the door; all they can't do is put a date on it. And, as I hope to have shown, that we can put a date on it is perfectly in keeping with enactivism ${ }^{28}$.

\footnotetext{
27 'A dog believes his master is at the door. But can he also believe his master will come the day after to-morrow? - And what can he not do here? - How do I do it?' (1997, PI, p. 174)

28 Thanks ....
} 


\section{References}

Bar-On, D. (2013) Expressive communication and Continuity Skepticism. Journal of Philosophy 110 (6), 293-330.

Barrett, L. (2018) Picturing Primates, and Looking at Monkeys: Why 21st Century Primatology Needs Wittgenstein. Phillnv 41: 161-187.

Byrne, R. (1999) The Thinking Ape: Evolutionary Origins of Intelligence. (Oxford: Oxford University Press).

Canfield, J. V.

--- (1995) The Rudiments of Language. Language and Communication 15:3, 195-211.

--- (2007) Becoming Human: The Development of Language, Self, and Self-Consciousness. (Basingstoke, UK: Palgrave Macmillan).

Cheney, D. \& Seyfarth, R.M. (1982) How vervet monkeys perceive their grunts. Animal Behaviour 30: 739-51.

Chomsky, N. (1988). Language and the problems of knowledge. The Managna Lectures. Cambridge, MA: MIT Press.

Cowley, S. (2007) The Cradle of Language: Making Sense of Bodily Connexions in Perspicuous Presentations: Essays on Wittgenstein's Philosophy of Psychology, ed. D. Moyal-Sharrock (Basingstoke, UK: Palgrave Macmillan, 2007), 278-98.

Dunbar, R. I. M.

--- (1993) Coevolution of neocortical size, group size and language in humans. Behavioral and Brain Sciences 16 (4): 681-735.

--- (1996) Grooming, gossip, and the evolution of language. Cambridge MA: Harvard UP.

--- (2003) The Social Brain: Mind, Language, and Society in Evolutionary Perspective. Annual Review of Anthropology 32:163-81.

Gallagher, S. (2012) In Defense of Phenomenological Approaches to Social Cognition: Interacting with the Critics. Rev.Phil.Psych. 3: 2, 187-212.

Gipps, R. (2004) Autism and Intersubjectivity: Beyond Cognitivism and the Theory of Mind. Philosophy, Psychiatry, \& Psychology, 11:3, 195-98.

Hacker, P. M. S. (2010). Wittgenstein's Anthropological and Ethnological Approach. In J. Padilla Galvez (ed.) Philosophical Anthropology: Wittgenstein's Perspective, 15-32. Ontos Verlag: Open Library.

Harrison S. J, et al (2013) Calling, Courtship, and Condition in the Fall Field Cricket. Gryllus pennsylvanicus' PLoS ONE 8(3)

http://journals.plos.org/plosone/article?id=10.1371/journal.pone.0060356

Hurford, J. R. (2004) Human uniqueness, learned symbols and recursive thought' European Review 12 (4): 551-565 (2004). 
Hutto, D. D. \& Satne, G.

--- (2015) Searching for the Natural Origins of Content: Challenging Research Project or Benighted Quest? Philosophia 43, 505-519.

Lancaster, J. B. (1975) Primate Behavior and the Emergence of Human Culture. New York: Holt, Rinehart and Winston.

Medina, José (2002) The Unity of Wittgenstein's Philosophy: Necessity, Intelligibility, and Normativity (Albany: SUNY)

Montgomery, D. E. (2002). Mental Verbs and Semantic Development. Journal of Cognition and Development, 3:4, 357-84.

McGinn, M. (1998) The Real Problem of Others: Cavell, Merleau-Ponty and Wittgenstein on Scepticism about Other Minds. European Journal of Philosophy 6:1, 45-58.

Michael, J (2011) Interactionism and Mindreading, Rev.Phil.Psych 2: 559-78.

Penn, D. C., K. J. Holyoak, and D. J. Povinelli (2008) Darwin's mistake: Explaining the discontinuity between human and nonhuman minds. Behavioral and Brain Sciences 31:109-178.

Plooij, F. (1978) Some Basic traits in Wild Chimpanzees in Action Gesture and Symbol ed. Andrew Lock. Academic Press: London, 111-32.

Richman, B.

--- (1976) Some vocal distinctive features used by gelada monkeys. Journal of the Acoustical Society of America 60: 718-724.

--- (1978) The synchronisation of voices by gelada monkeys. Primates 19: 569-581.

--- (1987) Rhythm and melody in gelada vocal exchanges. Primates 28: 199-223.

Seyfarth, R.M. \& Cheney, D.L.

--- (1984) Grooming, alliances and reciprocal altruism in vervet monkeys. Nature (London) 308: $541-543$.

--- (2014) The evolution of language from social cognition. Current Opinion in Neurobiology 28: 5-9.

Shapiro, L. (2014) Review of Radicalizing Enactivism: Basic Minds without Content, by Daniel D. Hutto and Erik Myin. Mind 123 (489): 213-220.

Sterelny, K. (2012) Language, gesture, skill: the co-evolutionary foundations of language. Phil. Trans. R. Soc. B 367, 2141-2151.

Tomasello, M.

--- (2014) A Natural History of Human Thinking. Harvard University Press.

--- (2016) Precis of A Natural History of Human Thinking. Journal of Social Ontology 2016, 2(1): 59-64.

Tomasello, M. et al (2016) Great apes anticipate that other individuals will act according to false beliefs. Science 354: 110-114. 
Whiten, A. \& R. W. Byrne (1988) Tactical deception in primates. Behavioral and Brain Sciences 11: 2, 233-44.

Wittgenstein, L.

--- (1977) On Certainty. G.E.M. Anscombe \& G.H. von Wright (eds.); D. Paul and G.E.M. Anscombe (trans.). Oxford: Blackwell. (OC)

--- (1978) Remarks on the Foundations of Mathematics, 3rd rev. edition. G.H. von Wright, R. Rhees \& G.E.M. Anscombe (eds.); G.E.M. Anscombe (trans.). Oxford: Blackwell. (RFM)

--- (1980a) Remarks on the Philosophy of Psychology, vol. I. G.E.M. Anscombe \& G.H. von Wright (eds.); G.E.M. Anscombe (trans.). Oxford: Blackwell. (RPP I)

--- (1980b) Remarks on the Philosophy of Psychology, vol. II. G.H. von Wright \& H. Nyman (eds.); C.G. Luckhardt \& M.A.E. Aue (trans.). Oxford: Blackwell. (RPP II)

--- (1988) Wittgenstein's Lectures on Philosophical Psychology 1946-47, notes by P.T. Geach, K.J. Shah and A.C. Jackson; ed. P.T. Geach. Hassocks: Harvester Press. (LPP)

--- (1992) Last Writings on the Philosophy of Psychology, vol II, ed. G.H. von Wright and H. Nyman, tr. C.G. Luckhardt and M.A.E. Aue. Oxford: Blackwell. (LW II)

--- (1993) Cause and Effect: Intuitive Awareness. In J.C. Klagge and A. Nordman (eds.), Philosophical Occasions: 1912-1951, 371-426. Indianapolis: Hackett Publishing. (CE)

--- (1997) Philosophical Investigations, 2nd Edition. G.E.M. Anscombe (trans.). Oxford: Blackwell, (PI)

--- (2001) Wittgenstein's Lectures: Cambridge, 1932-1935. A. Ambrose (ed.). Oxford: Basil Blackwell, 1979. (AWL)

--- (2005) The Big Typescript: TS 213, ed. \& trans. by C. G. Luckhardt \& M.A.E. Aue. Oxford: Blackwell Publishing. (BT)

Zahavi, D. \& Satne, G. (2016) Varieties of shared intentionality: Tomasello and classical phenomenology. In Bell, et al (eds), Beyond the Continental-Analytic Divide, Routledge, 2016, 305-25. 